\title{
Micropropagtion and DNA-barcoding of the endangered endemic Phlomis aurea plant of Saint Katherine
}

\author{
Heba El-Sayed Ghareb ${ }^{1}$, Shafik Darwish Ibrahim ${ }^{2}$ and Ghada Abd EI-Moneim Hegazi ${ }^{1}$ \\ ${ }^{1}$ Tissue Culture Unit, Department of Genetic Resources, Desert Research Center, El-Matareya, Cairo, Egypt \\ ${ }^{2}$ Agricultural Genetic Engineering Institute, Agricultural Research Center, Giza, Egypt
}

Abstract

Saint Katherine is considered a "biodiversity hotspot" because of the high level of endemism of reported plant species. In this study, conservation of the endangered endemic plant; Phlomis aurea of Saint Katherine, Southern Sinai, Egypt, was carried out through micropropagation and DNA barcoding. The first efficient micropropagation protocol for Phlomis aurea was established as a mean of ex situ conservation of the plant. Shoot tips and nodal segments of in vitro germinated seedlings were established on Murashige and Skoog medium supplemented with $0.54 \mu \mathrm{M} \beta$-naphthalene acetic acid (NAA) and $2.46 \mu \mathrm{M}$ N6-(2-isopentenyl) adenine (2iP) in combination with 6-benzylaminopurine (BA) or kinetin (Kin). The medium supplemented with $3.48 \mu \mathrm{M}$ Kin considered optimum for both explants. For multiplication, BA was the most efficient cytokinin. The percentage of rooted explants reached $100 \%$ at the concentration of $14.7 \mu \mathrm{M}$ indolebutyric acid (IBA), whereas the highest number of roots was recorded for 4.90 $\mu \mathrm{M}$, which considered the optimum concentration with a percentage of $80 \%$ of rooting. Rooted plantlets were transplanted in the greenhouse with $75 \%$ survival rate. The present study also aimed to carry out DNA barcoding of Phlomis aurea for accurate identification to provide a database for establishing an efficient conservation program for the plant. Three chloroplast DNA markers were used [ribulose-1,5-bisphosphate carboxylase/oxygenase large subunit ( $r b c L$ ), maturase $\mathrm{K}$ (matK) and RNA polymerase C1 $(r p o C 1)]$ and all were successful in amplifying target regions, however the performance of both $r b c L$ and matK markers seemed to be species-specific. The similarity percentage was maximum for $r b c L(99.81 \%)$ and matK $(100 \%)$ compared to the database of the same species.

Keywords: DNA barcoding; Lamiaceae; micropropagation; Sinai Jerusalem Sage; Southern Sinai.

Abbreviations: BA_6_benzylaminopurine; BLAST_Basic Local Alignment Tool; CBOL_Consortium for the Barcode of Life; IBA_ indolebutyric acid; 2iP_N6_(2_isopentenyl) adenine; IUCN_International Union for Conservation of Nature; Kin_kinetin; matK_ maturase K; MS Murashige and Skoog; NAA_ $\beta$ naphthaleneacetic acid; NCBI National Centre of Biotechnology Information; $r b c L_{-}$ribulose_1,5_bisphosphate carboxylase/oxygenase large subunit; rpoC1_RNA polymerase C1.

Introduction

The protection of endemic species is a worldwide need; endemic species are regularly the most defenseless plant species against the dangers of unmanaged human activities, due to their exceptional transformative history and low population size (Omar, 2017). Phlomis aurea Decne. is a wild golden-woolly perennial shrub, known as Sinai Jerusalem Sage and its Vernacular name is Awarwar, belonging to Lamiaceae family. According to the International Union for Conservation of Nature (IUCN, 2019), Phlomis aurea is an endangered species that needs an urgent conservation plan. It is classified as endangered, because it is endemic to the high mountain area of Saint Katherine Protectorate in Southern Sinai, Egypt and found just in two locations (Boulos, 2008). There is a continuing decline in the number of plant individuals because of the deterioration of habitat quality for this species, the destructive effect of climate change, drought, human activities such as over-collection for its economic importance and uprooting (Khafagi et al., 2012; Shabana, 2013). Because of these threads, the wild population of Phlomis aurea can be in extreme danger in the near future (Omar, 2017).
Genus Phlomis comprises about 100 species in the world, restricted to Mediterranean region to central Asia and China. Only two Phlomis species occur in Egypt; Phlomis aurea and Phlomis floccosa D. Don. (Täckholm, 1974; Boulos, 2002). Phlomis has been utilized by the Egyptian people in folk medicine as a sedative, stimulant, immune-suppressive, hemorrhoids, free radical scavenger, astringent, hemorrhoid, anti-diarrheal, anti-inflammatory, antimicrobial, anti-malarial, anti-diabetic, anti-mutagenic, anticough, anti-nociceptive, for mending of wound and to treat ulcers, gastric, intestinal and abdominal pains (Amor et al., 2009). Some Phlomis species are consumed as a tea in Mediterranean region (Serag et al., 2018). Genus Phlomis contains essential oil, phenolics and flavonoids, therefore the plant possesses antioxidant activity (Sobeh et al., 2016; Merouane et al., 2018). Also, because of the active constituents in the plant species, it has antibacterial (Turker and Yldrm, 2013; Bajalan et al., 2017), antifungal (Asgarpanah et al., 2017) and cytotoxic (Sobeh et al, 2016; Sarkhail et al., 2017) activities. Phlomisoside F is isolated from $P$. younghusbandii and is a promising potential anti- 
inflammatory drug (Li et al., 2015). Moreover, diverse classes of glycosides including diterpenoids, phenylpropanoids, phenylethanoids and flavonoids had been described from genus Phlomis. Many of the phenyl propanoids showed biological significances, e.g. immunosuppressant, cytotoxic anti-inflammatory and antimicrobial activities (Serag et al., 2018).

Phlomis aurea is a chamaephyte and is used in the traditional medicine. It is aromatic and its essence can be promising in different industries as it is still an unknown species to trade. The plant species has a significant medicinal and ecological importance. Medicinally, the plant has anti-microbial, anti-diabetic, anti-inflammatory, immune-suppressant and cytostatic properties. Flavonoids had been recognized from that plant. Ecologically, Phlomis aurea is characteristic to arid lands and has a role in pollination due to its lipped flower that attracted honey bees (Serag et al., 2018). The plant is also used as fuel (Shabana, 2013) and as fodder for animals (Omar, 2017). Iridoid and megastigmane glycosides were extracted from the plant (Kamel et al., 2000).

Both in situ and ex situ conservation strategies are urgently needed to be applied in parallel to rare and endangered plant species, especially that are endemic to a specific area. One of the most efficient ex situ conservation methods is micropropagation of the target plant. Although, propagation by seeds and seed banking from different populations is extremely important for conserving genetic variations and reducing the chance of extinction of a plant population at a site (Bakker and Berendse, 1999), micropropagation is essential and has many advantages. It is particularly essential for conserving the plant species that do not produce seeds or that have recalcitrant seeds (Oseni, et al., 2018). Furthermore, it produces hundreds of plants in a limited space and comparatively short time, regardless of the season or weather (Akin-Idowu et al., 2009).

There could be a severe decline in the population of Phlomis aurea with time, unless precautions have been taken. In order to establish an efficient conservation program for a target plant species, providing a database on its biology and ecology is a must (Shaltout et al., 2016). For biodiversity conservation, accurate taxonomic assignment is important. DNA-based identification (barcoding) is simple and free from subjective errors, which is not the case in morphological identification. The phylogeny of the genus Phlomis was studied by Mathiesen et al. (2011) using trnL-F and rpsl6 intron and retrieved low interspecific resolution. El-Banhawy and Al-Juhani (2019) obtained equivalent results using DNA sequences of two chloroplast markers; psb-A/trn-H and $r b c L$ to reconstruct the phylogeny of genus Phlomis alongside the endemic Phlomis aurea and they strongly recommended using other markers.

According to the critical situation of Phlomis aurea as an endangered species and also as an endemic plant, restricted to Saint Katherine, the aim of the study was to establish an effective conservation program for the plant through micropropagation and DNA barcoding. To our knowledge, this is the first report on the micropropagation of Phlomis aurea.

\section{Results and Discussion}

\section{Micropropagation of Phlomis aurea}

In vitro germination percentage of Phlomis aurea seeds was $90 \%$. Germination began seven days after the seeds were planted on Murashige and Skoog (MS; Murashige and Skoog, 1962) medium (Fig 1A). The presence of contamination was limited (20\%), which did not represent a problem for germination. About $82 \%$ survival from contamination has been achieved. Shoot tips and stem nodal segments were excised from one-month old seedlings and transferred to the different establishment media for the micropropagation. Seedlings are the most preferred material for use to establish in vitro cultures when the objective is plant conservation for maximizing genetic diversity of the produced plants, which is desirable (Fay, 1994).

\section{Culture establishment}

Shoot tips and stem nodal segments established in vitro on all the tested treatments (Table 1 ). For shoot tips, survival percentage ranged between 63 and 100\%. Growth percentage of the survived explants reached $100 \%$ on MS medium supplemented with $0.54 \mu \mathrm{M}$ NAA and $2.46 \mu \mathrm{M} 2 \mathrm{iP}$ only and with the addition of 1.11 or $3.33 \mu \mathrm{M}$ BA or $3.48 \mu \mathrm{M}$ Kin. Mean number of axillary shoots explant ${ }^{-1}$ was significantly the maximum of 6 axillary shoots when the medium was supplemented with $2.22 \mu \mathrm{M}$ BA, but the mean length of axillary was the least $(0.25 \mathrm{~cm})$ on the same medium, comparing to the tested treatments. The concentration of $2.32 \mu \mathrm{M}$ Kin ranked next and gave 4 axillary shoots explant ${ }^{-1}$. The significantly longest axillary shoot of $3.5 \mathrm{~cm}$ was obtained on the nutrient medium supplemented with $3.48 \mu \mathrm{M}$ Kin and gradually became shorted by decreasing Kin concentration. The same observation was recorded with Teucrium capitatum (Papafotiou and Martini, 2016).

It was noticed that the media containing BA gave axillary shoots suffering from vitrification, which is not favourable for further stages. Therefore, MS medium supplemented with $0.54 \mu \mathrm{M}$ NAA and $2.46 \mu \mathrm{M} 2 \mathrm{iP}$ in addition to $3.48 \mu \mathrm{M}$ Kin considered the best establishment medium of shoot tips. Concerning stem nodal segments, the survival percentage and growth percentage of the survived explants ranged between 50 and $100 \%$. MS medium supplemented with 0.54 $\mu \mathrm{M}$ NAA and $2.46 \mu \mathrm{M} 2 \mathrm{iP}$ in addition to $3.33 \mu \mathrm{M}$ BA produced the highest number of axillary shoots of 4.5 explant $^{-1}$. This number decreased by decreasing the concentration of BA.

Concerning the mean length of axillary shoots, it attained its significantly maximum value of $2.75 \mathrm{~cm}$ on MS medium supplemented with $3.48 \mu \mathrm{M}$ Kin, with a mean of 3.5 axillary shoots explant ${ }^{-1}$.

In general, plant growth regulators are crucial in regulating differentiation and organogenesis. Tsafouros and Roussos (2019) reported that in many plants, the supplementation of the nutrient medium with only cytokinins is not sufficient to induce the formation of axillary shoots. Synthetic auxins, such as NAA are utilized in combination with cytokinin in the micropropagation of many plant species with better results than cytokinin individually (Akhtar et al., 2016). It is well established that the nutrient media supplemented with cytokinin promotes shoot formation and a higher ratio of cytokinin to auxin is required for shoot regeneration (Rosspopoff et al., 2017; Pernisova et al., 2018). Combining NAA with BA enhances shoots proliferation in many other species such as Clitoria ternatea (Rout, 2004), Prunella vulgaris (Rasool et al., 2009) and Cymbopogon schoenanthus (Abdelsalam et al., 2017).

A preliminary study on the establishment of Phlomis aurea shoot tips and stem nodal segments was carried out using 
only BA or Kn with NAA and resulted in dwarf axillary shoots. The addition of 2iP to the medium enhanced the elongation. It is well known that a synergistic effect of different cytokinins can result in effective regeneration rates (Pernisova et al., 2009, 2018).

The length of axillary shoots is more important in this stage than their number. The aim of this stage is obtaining axillary shoots that could be handled and divided into nodal sections to be transferred to the multiplication medium for proliferation. Therefore, the medium supplemented with $3.48 \mu \mathrm{M}$ Kin considered optimum for the in vitro establishment of both shoot tip and stem nodal segment explants of Phlomis aurea (Fig 1B and C). This confirms the significant role for Kin in shoot formation and regeneration (Wang et al., 2018). The results are in harmony with Tsafouros and Roussos (2019), who clarified the adenine efficiency and found that BA induced high number of nodes and Kin characterized by the high shoot length induction.

\section{Multiplication}

Table (2) shows the results of culturing the axillary shoots developed from the establishment stage on different concentrations of BA, Kin or 2iP supplemented medium. These cytokinins were chosen in this experiment because there are the most widely used cytokinin (Yancheva and Kondakova, 2016). In this experiment, the concentrations of cytokinins were reduced in comparison to the establishment stage to eliminate the vitrification of axillary shoots that was observed at the higher concentrations of BA. For the multiplication stage, it is important to select a proper concentration of cytokinin, because higher concentrations cause a reduction in shoot size, somaclonal variations and vitrification (Lebedev et al., 2019).

Multiplication of axillary shoots was affected both by cytokinin type and its concentration. All tested treatments produced axillary shoots. The highest recorded mean number of axillary shoots explant ${ }^{-1}$ was obtained on MS medium supplemented with $1.78 \mu \mathrm{M}$ BA. Decreasing the concentration of $\mathrm{BA}$ in the nutrient medium gradually decreased the number of axillary shoots. Concerning the other tested cytokinins; 2iP ranked next as it produced higher number of axillary shoots than Kin. For both, the number of axillary shoots increased by increasing their concentration. The present study indicated that the number of axillary shoots was directly correlated to the cytokinin concentration. The same observation was recorded for Dendrocalamus giganteus (Devi et al., 2012) and Ziziphora tenuior (Dakah et al., 2014). It is obvious that the correct choice of cytokinin is one of the most important factors in the multiplication of axillary shoots and it varied from species to another. It is well known that cytokinins play multiple roles in the development of plant; such as induction of cell division and enlargement and stimulation of protein synthesis and enzymes activity (Arab et al., 2014).

The maximum mean length of axillary shoots was $2.6 \mathrm{~cm}$ on MS medium supplemented with $0.93 \mu \mathrm{M}$ Kin, but it is insignificantly different compared to the best medium for multiplication. Therefore, MS medium supplemented with $1.78 \mu \mathrm{M}$ BA considered the optimum for axillary shoots multiplication (Fig 1D).

The variation in the effectiveness of different cytokinins could be partly assigned to their different metabolism within the plant. In this study, BA was more appropriate for shoot multiplication than Kin or 2iP. Higher shoot promoting ability of BA compared with Kin and 2iP has also been reported for other Lamiaceae species; Teucrium capitatum (Papafotiou and Martini, 2016), or compared with Kin as for Salvia fruticosa (Arikat et al., 2004), Ocimum kilimandscharicum (Saha et al., 2010) and Thymus satureioides (Aicha et al., 2013). Also, BA induced higher shoot production compared with $2 \mathrm{iP}$ in Sideritis athoa (Papafotiou and Kalantzis, 2009). Moreover, BA induced multiplication in many Lavandula species (Zuzarte et al., 2010; Gonçalves and Romano, 2013). The high efficiency of BA could be attributed to that it is not a suitable substrate of cytokinin oxidase, the enzyme responsible for the endogenous cytokinin balance (Kieber and Schaller, 2004; George et al., 2008; Tsafouros and Roussos, 2019). Some of the conjugated forms of BA produced during BA metabolism, extending the action of BA. Furthermore, BA considered as the most stable among the tested cytokinins because of that the stability of the aromatic side chain substituted at N6 is higher than the isoprenoid chain of 2iP, the furan chain of Kin (Zhang et al., 2010; Tsafouros and Roussos, 2019).

\section{Rooting and acclimatization}

Rooting percentage was positively affected by increasing the concentration of IBA (Table 3). It reached $100 \%$ using 14.7 $\mu \mathrm{M}$ IBA in half strength MS medium, while the medium without IBA produced the lowest rooting percentage (only $40 \%)$. However, the mean number and length of roots explant $^{-1}$ were maximum at the concentration of $4.90 \mu \mathrm{M}$ IBA (Fig 1E). The number of roots is an important factor for increasing the percentage of plant survival during acclimatization stage and considered a sign of qualitative rooting response (Dolcet-Sanjuan et al., 2004). Therefore, the concentration of $4.90 \mu \mathrm{M}$ IBA considered the optimum concentration for the rooting of Phlomis aurea, although it produced lower percentage of rooting $(80 \%)$. It is well known that rooting response depends on many factors, among which the type of auxin used, the applied concentration, the species or even the clone of a specific species (Dolcet-Sanjuan et al., 2004). Regarding to other species from Lamiaceae family, many plant species rooted on medium supplemented with only IBA; such as Teucrium capitatum rooted at higher percentages when cultured on $1 / 2$ strength MS medium supplemented with IBA, regardless of its concentration (Papafotiou and Martini, 2016), with 4.90 $\mu \mathrm{M}$ IBA for Teucrium stocksianum (Bouhouche and Ksiksi, 2007) and 2.46 $\mu \mathrm{M}$ IBA for Teucrium fruticans (Frabetti et al., 2009). Sideritis athoa was difficult to root and the best rooting (46 to 53\%) was achieved with $9.80 \mu \mathrm{M}$ IBA (Papafotiou and Kalantzis, 2009).

Rooted plantlets were transplanted into pots and gradually transferred from the growth chamber to the greenhouse with $75 \%$ survival rate (Fig 1 F).

\section{DNA barcoding of Phlomis aurea}

It is highly important to distinguish and recognize the endemic species to help in the conservation of natural resources, especially the medicinally important species such as Phlomis aurea (de Groot et al., 2011), from Wadi El Arbaien, Saint Katherine, Southern Sinai. DNA barcoding is a reliable approach to verify a plant identity; a short genetic sequence from a standard part of the genome can be sufficient for plant species identification. The outputs of BLAST matching and tree analysis of Phlomis aurea are represented in Tables (4, 5 and 6) and Fig (2, 3, 4 and 5) for 
Table 1. Effect of MS medium supplemented with $0.54 \mu \mathrm{M}$ NAA and $2.46 \mu \mathrm{M}$ 2iP in addition to BA or Kin at different concentrations on the in vitro establishment of Phlomis aurea shoot tip and nodal segment explants.

\begin{tabular}{|c|c|c|c|c|c|c|c|c|c|c|}
\hline \multirow[t]{2}{*}{ Treatments } & \multirow{2}{*}{$\begin{array}{l}\text { Cytokinin conc. } \\
(\mu \mathrm{M}) \\
\mathrm{BA}\end{array}$} & \multirow[b]{2}{*}{ Kin } & \multicolumn{4}{|l|}{ Shoot tip } & \multicolumn{3}{|c|}{ Stem nodal segment } & \multirow[b]{2}{*}{$\begin{array}{l}\text { Mean length of } \\
\text { axillary shoots }(\mathrm{cm})\end{array}$} \\
\hline & & & Survival (\%) & Growth (\%) & $\begin{array}{l}\text { Mean no. of } \\
\text { axillary shoots } \\
\text { explant }^{-1}\end{array}$ & $\begin{array}{l}\text { Mean } \\
\text { length of } \\
\text { axillary } \\
\text { shoots }(\mathrm{cm})\end{array}$ & Survival (\%) & $\begin{array}{l}\text { Growth } \\
\text { (\%) }\end{array}$ & $\begin{array}{l}\text { Mean no. of axillary } \\
\text { shoots explant }{ }^{-1}\end{array}$ & \\
\hline T1 & 0.00 & 0.00 & 100 & 100 & $3.25^{b}$ & $1.52^{\mathrm{b}}$ & 75 & 100 & $2.88^{b}$ & $0.67^{c}$ \\
\hline T2 & 1.11 & 0.00 & 100 & 100 & $3.25^{\mathrm{b}}$ & $1.75^{\mathrm{b}}$ & 100 & 100 & $3.13^{b}$ & $0.65^{c}$ \\
\hline T3 & 2.22 & 0.00 & 100 & 75 & $6.01^{\mathrm{a}}$ & $0.25^{\mathrm{c}}$ & 75 & 100 & $3.31^{\mathrm{ab}}$ & $0.94^{c}$ \\
\hline T4 & 3.33 & 0.00 & 63 & 100 & $2.00^{c}$ & $0.52^{c}$ & 100 & 75 & $4.50^{\mathrm{a}}$ & $0.30^{c}$ \\
\hline T5 & 0.00 & 1.16 & 100 & 75 & $1.63^{c}$ & $1.25^{\mathrm{b}}$ & 50 & 100 & $3.13^{b}$ & $0.40^{c}$ \\
\hline T6 & 0.00 & 2.32 & 100 & 75 & $4.00^{b}$ & $1.70^{\mathrm{b}}$ & 100 & 75 & $3.88^{\mathrm{ab}}$ & $1.74^{\mathrm{b}}$ \\
\hline T7 & 0.00 & 3.48 & 75 & 100 & $1.50^{\mathrm{C}}$ & $3.50^{\mathrm{a}}$ & 75 & 50 & $3.50^{\mathrm{ab}}$ & $2.75^{\mathrm{a}}$ \\
\hline
\end{tabular}
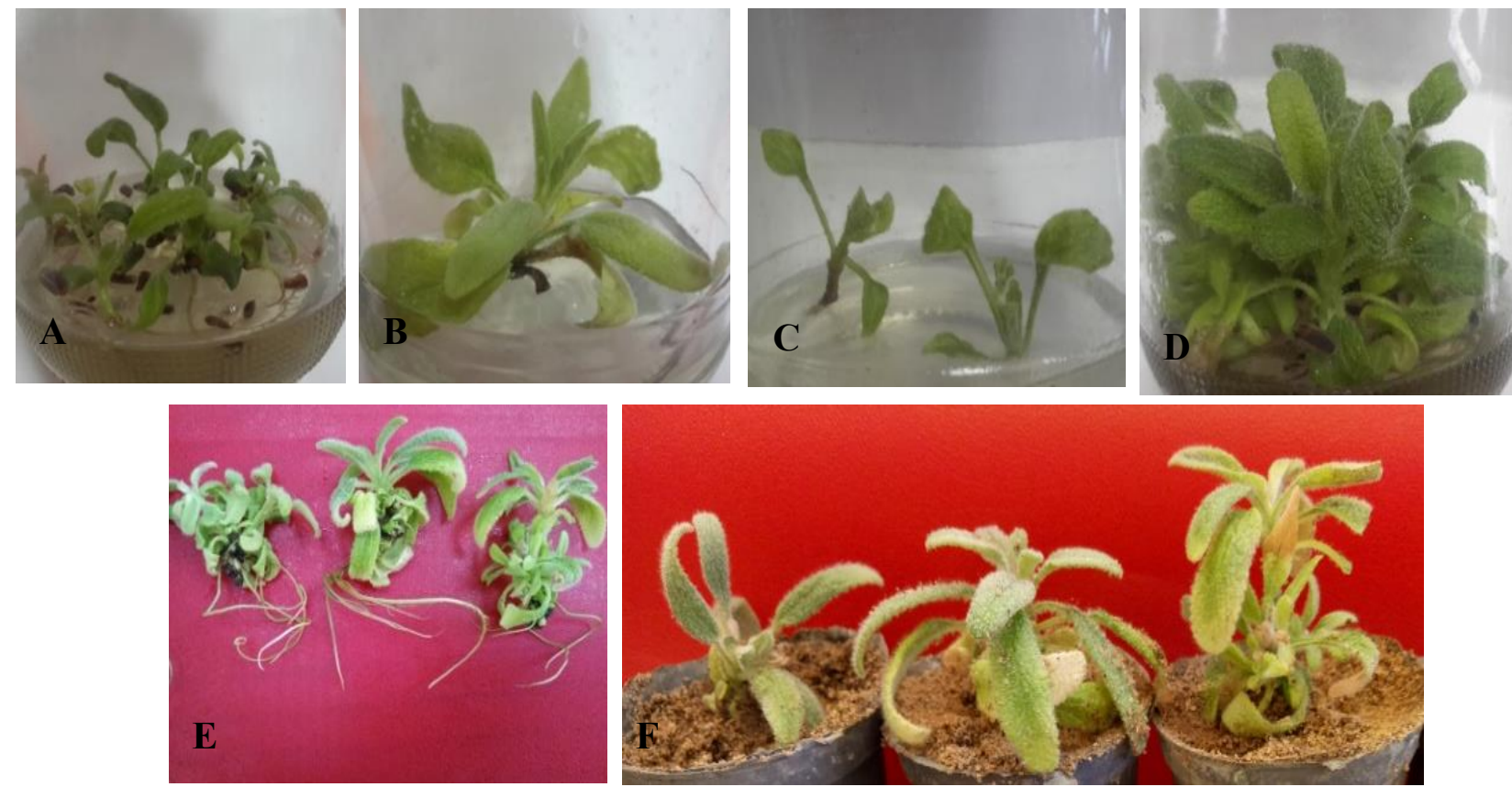

Fig 1. Phlomis aurea in vitro propagation stages. (A) Germinated seeds, (B) established shoot tip, (C) Established stem nodal segments. (D) Multiple shoots, (E) Development of roots (F) Acclimatized plantlets grown in greenhouse. 


\begin{tabular}{|c|c|c|c|c|c|}
\hline \multirow[t]{2}{*}{ Treatments } & \multicolumn{3}{|c|}{$\begin{array}{l}\text { Cytokinin conc. } \\
\qquad(\mu \mathrm{M})\end{array}$} & \multirow[t]{2}{*}{$\begin{array}{l}\text { Mean no. of axillary shoots } \\
\text { explant }^{-1}\end{array}$} & \multirow[t]{2}{*}{ Mean length of axillary shoots $(\mathrm{cm})$} \\
\hline & BA & Kin & $2 \mathrm{iP}$ & & \\
\hline T1 & 0.00 & 0.00 & 0.00 & $2.4^{\mathrm{e}}$ & $1.90^{\mathrm{ab}}$ \\
\hline T2 & 0.44 & 0.00 & 0.00 & $2.2^{\mathrm{e}}$ & $2.20^{\mathrm{ab}}$ \\
\hline T3 & 0.89 & 0.00 & 0.00 & $3.6^{d}$ & $2.20^{\mathrm{ab}}$ \\
\hline $\mathrm{T} 4$ & 1.78 & 0.00 & 0.00 & $7.4^{\mathrm{a}}$ & $2.15^{\mathrm{ab}}$ \\
\hline T5 & 0.00 & 0.46 & 0.00 & $2.2^{\mathrm{e}}$ & $2.15^{\mathrm{ab}}$ \\
\hline T6 & 0.00 & 0.93 & 0.00 & $2.6^{\mathrm{e}}$ & $2.60^{\mathrm{a}}$ \\
\hline T7 & 0.00 & 1.86 & 0.00 & $3.4^{\mathrm{d}}$ & $1.71^{\mathrm{ab}}$ \\
\hline T8 & 0.00 & 0.00 & 0.49 & $3.6^{d}$ & $1.31^{\mathrm{b}}$ \\
\hline T9 & 0.00 & 0.00 & 0.98 & $5.2^{c}$ & $1.45^{\mathrm{b}}$ \\
\hline $\mathrm{T} 10$ & 0.00 & 0.00 & 1.97 & $6.0^{\mathrm{b}}$ & $1.10^{\mathrm{b}}$ \\
\hline
\end{tabular}

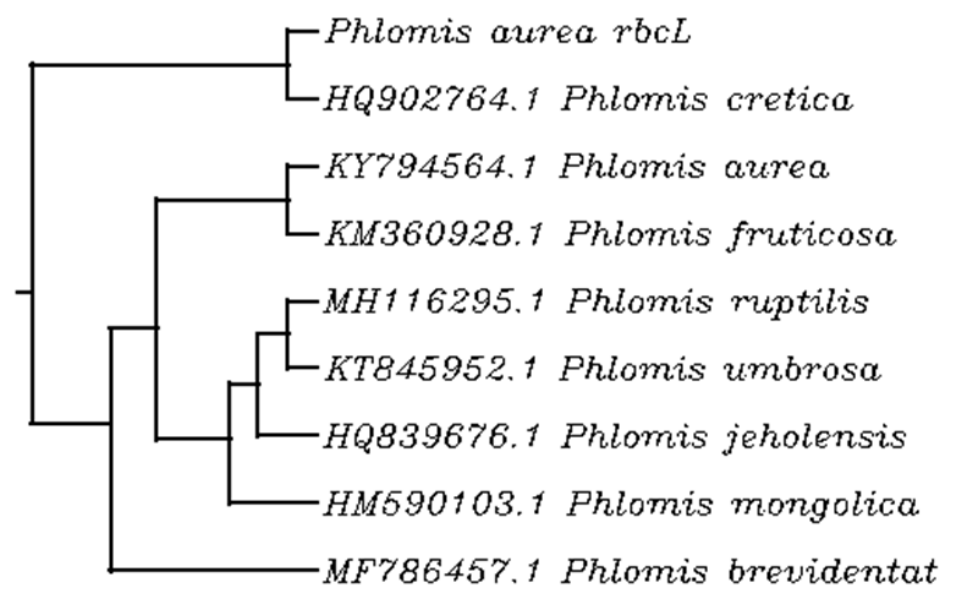

Fig 2. Phylogenetic tree of Phlomis aurea using the cpDNA marker; $r b c L$ showing names of plant species and accession numbers. 
Table 3. Effect of $1 / 2 \mathrm{MS}$ medium supplemented with IBA at different concentrations on the rooting of Phlomis aurea axillary shoots.

\begin{tabular}{lcccc}
\hline Treatments & IBA conc. $(\mu \mathrm{M})$ & Rooting $(\%)$ & $\begin{array}{c}\text { Mean no. of roots } \\
\text { explant }\end{array}$ \\
\hline T1 & & & $1.0^{\mathrm{b}}$ & Mean length of roots (cm) \\
T2 & 0.00 & 40 & $1.6^{\mathrm{b}}$ & $4.7^{\mathrm{a}}$ \\
T3 & 2.46 & 60 & $3.7^{\mathrm{a}}$ & $5.7^{\mathrm{a}}$ \\
T4 & 4.90 & 80 & $1.0^{\mathrm{b}}$ & $5.1^{\mathrm{a}}$ \\
T5 & 9.80 & 80 & $1.4^{\mathrm{b}}$ & $4.8^{\mathrm{a}}$ \\
\hline
\end{tabular}

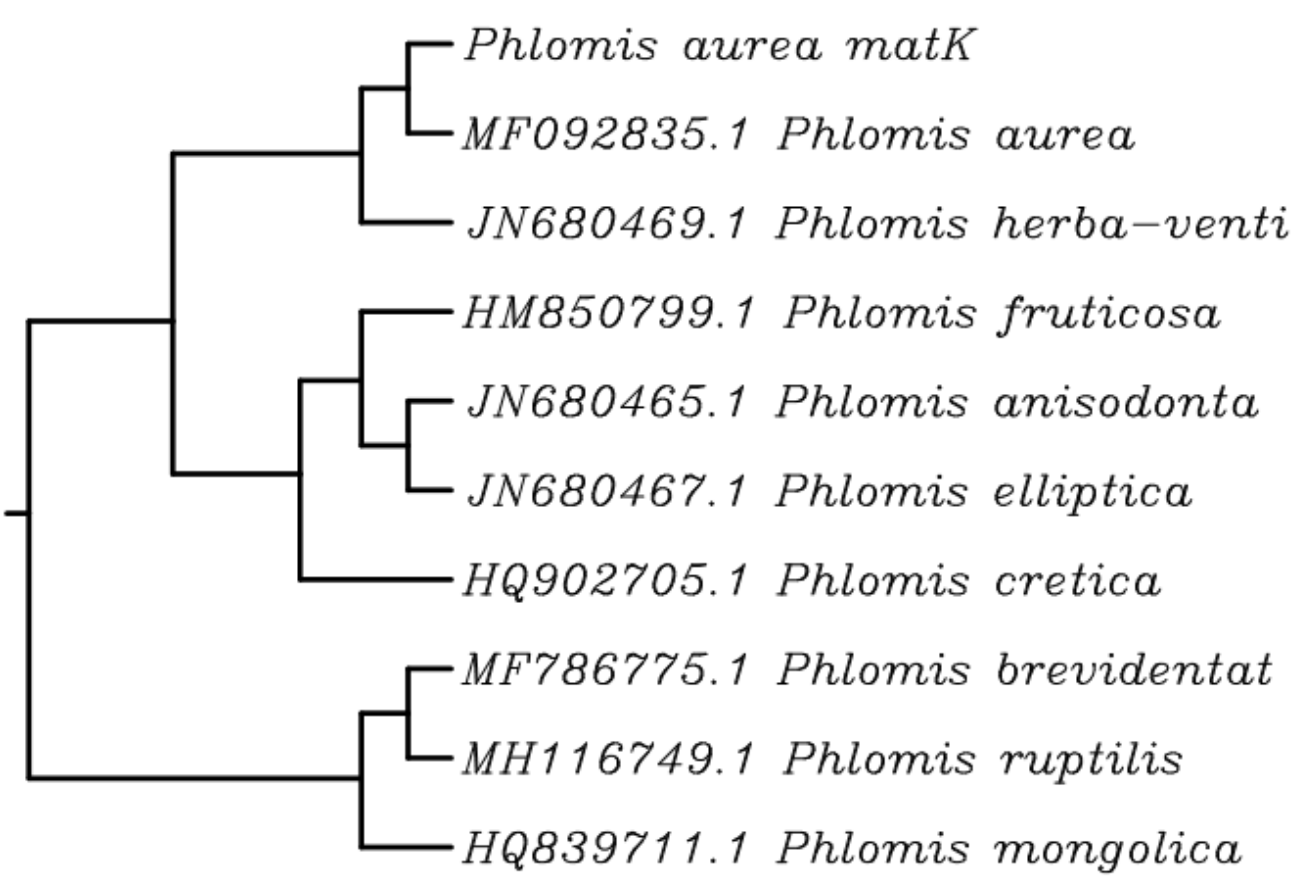

Fig 3. Phylogenetic tree of Phlomis aurea using the cpDNA marker; matK, showing names of plant species and accession numbers. 


\begin{tabular}{lcccc}
\multicolumn{4}{l}{ Table 4. $r b c$ DNA barcode of related plant species with similarity percentage of more than $98.3 \%$, downloaded from GenBank database. } \\
\hline Plant species & Accession no. & E-value & Query coverage (\%) & Similarity (\%) \\
\hline Phlomis aurea & KY794564.1 & 0.0 & 76 & 99.81 \\
Phlomis fruticosa & KM360928.1 & 0.0 & 78 & 98.90 \\
Phlomis ruptilis & MH116295.1 & 0.0 & 78 & 98.53 \\
Phlomis umbrosa & KT845952.1 & 0.0 & 76 & 99.43 \\
Phlomis jeholensis & HQ839676.1 & 0.0 & 78 & 98.53 \\
Phlomis mongolica & HM590103.1 & 0.0 & 78 & 98.53 \\
Phlomis cretica & HQ902764.1 & 0.0 & 75 & 99.43 \\
Phlomis brevidentata & MF786457.1 & 0.0 & 76 & 98.31 \\
\hline
\end{tabular}

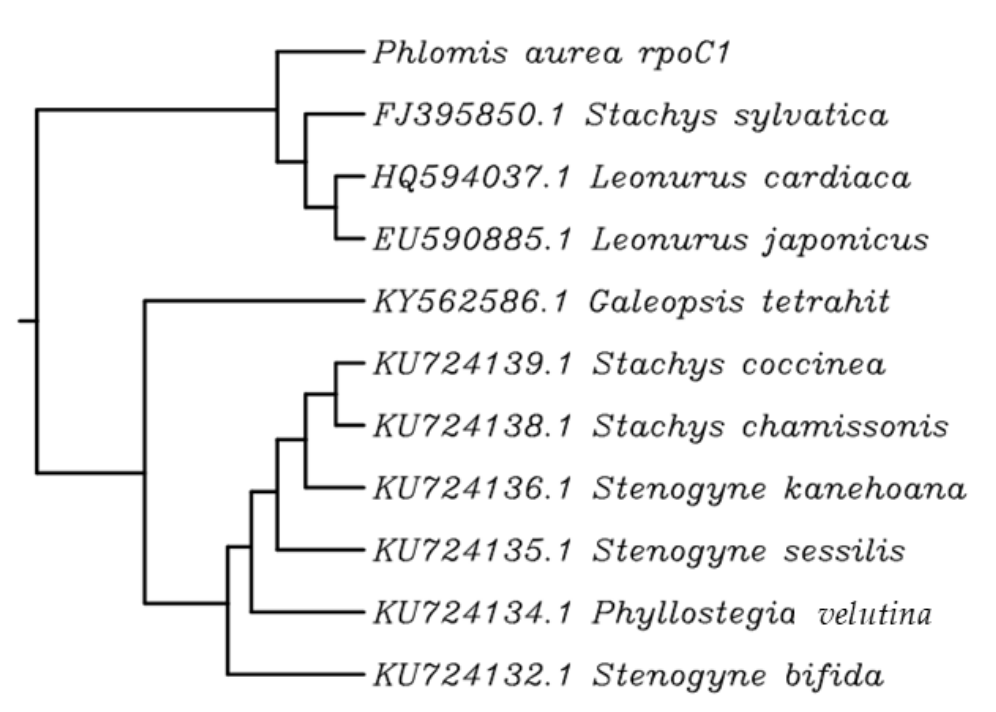

Fig 4. Phylogenetic tree of Phlomis aurea using the cpDNA marker; rpoC1, showing names of plant species and accession numbers. 
Table 5. matK DNA barcode of related plant species with similarity percentage of more than $97.5 \%$, downloaded from GenBank database.

\begin{tabular}{|c|c|c|c|c|}
\hline Plant species & Accession no. & E-value & $\begin{array}{l}\begin{array}{c}\text { Query coverage } \\
(\%)\end{array} \\
\end{array}$ & $\begin{array}{c}\text { Similarity } \\
(\%)\end{array}$ \\
\hline Phlomis fruticosa & HM850799.1 & 0.0 & 85 & 99.51 \\
\hline Phlomis cretica & HQ902705.1 & 0.0 & 84 & 99.26 \\
\hline Phlomis brevidentata & MF786775.1 & 0.0 & 81 & 97.95 \\
\hline Phlomis mongolica & HQ839711.1 & 0.0 & 80 & 97.54 \\
\hline Phlomis ruptilis & MH116749.1 & 0.0 & 68 & 98.16 \\
\hline Phlomis anisodonta & JN680465.1 & 0.0 & 63 & 99.84 \\
\hline Phlomis elliptica & JN680467.1 & 0.0 & 64 & 99.67 \\
\hline Phlomis herba-venti & JN680469.1 & 0.0 & 63 & 99.51 \\
\hline Phlomis aurea & MF092835.1 & $2 \mathrm{e}-131$ & 26 & 100 \\
\hline
\end{tabular}

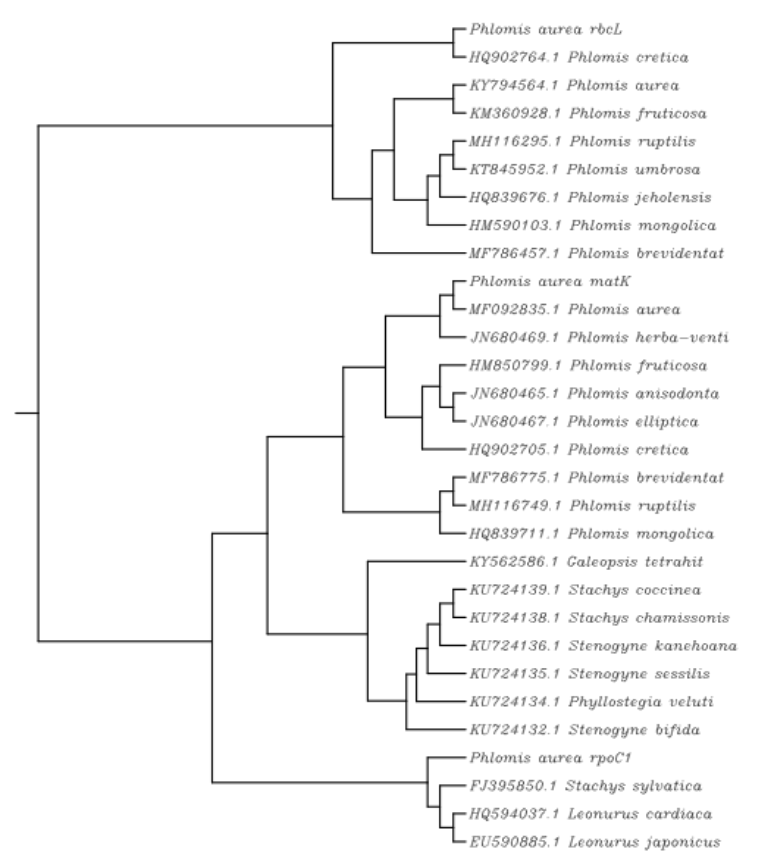

Fig 5. Phylogenetic tree of Phlomis aurea using the three cpDNA markers; rbcL, matK and rpoC1 (combined data) showing names of plant species and accession numbers. 
Table 6. rpoC1 DNA barcode of related plant species with similarity percentage of more than $97 \%$, downloaded from GenBank database.

\begin{tabular}{|c|c|c|c|c|}
\hline Plant species & Accession no. & E-value & Query coverage (\%) & Similarity (\%) \\
\hline Galeopsis tetrahit & KY562586.1 & 0.0 & 94 & 97.57 \\
\hline Stachys sylvatica & FJ395850.1 & 0.0 & 94 & 97.36 \\
\hline Stachys coccinea & KU724139.1 & 0.0 & 94 & 97.36 \\
\hline Stachys chamissonis & KU724138.1 & 0.0 & 94 & 97.36 \\
\hline Stenogyne kanehoana & KU724136.1 & 0.0 & 94 & 97.36 \\
\hline Stenogyne sessilis & KU724135.1 & 0.0 & 94 & 97.36 \\
\hline Phyllostegia velutina & KU724134.1 & 0.0 & 94 & 97.36 \\
\hline Stenogyne bifida & KU724132.1 & 0.0 & 94 & 97.36 \\
\hline Leonurus cardiaca & HQ594037.1 & 0.0 & 89 & 98.51 \\
\hline Leonurus japonicus & EU590885.1 & 0.0 & 89 & 98.50 \\
\hline
\end{tabular}

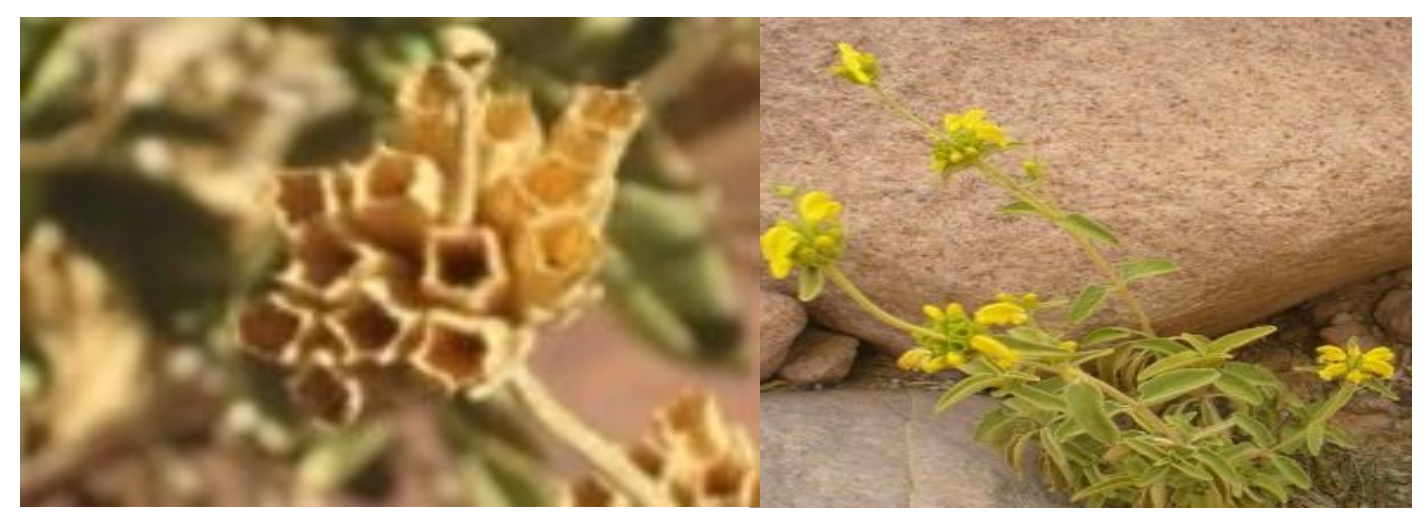

Fig 6. Phlomis aurea grown naturally in Wadi El Arbaien, Saint Katherine, Southern Sinai showing flowers with a close up view of a fruit. 


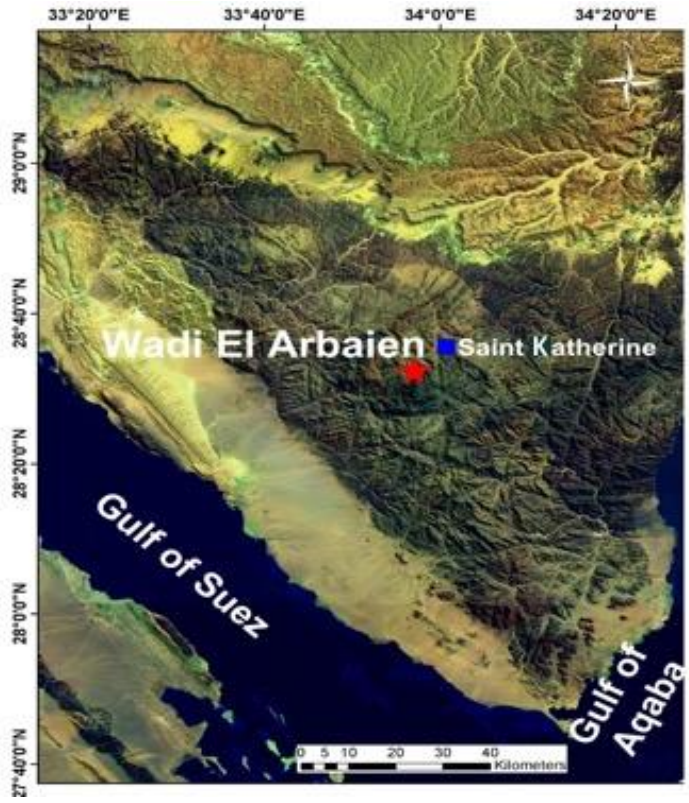

Fig 7. A map showing the location of Phlomis aurea at Wadi El Arbaien, Saint Katherine, South Sinai, Egypt.

the plant species that have the highest percentages of similarity. The newly generated sequences of the three cpDNA markers; rbcl, matK and rpoC1 were used as barcodes. The maximum query coverage percentages were 78,85 and $94 \%$ for $r b c L$, matK and rpoC1, respectively. de Groot et al. (2011) recommended that species identification is considered successful when the percentage of similarity scores more than $95 \%$ and involves a single species. Also, on the generic level, DNA barcoding is considered successful when all BLAST searches score more than $95 \%$ similarity and include a single genus (de Groot et al., 2011). In the present study, the maximum similarity percentages were $99.81 \%$ for rbcl, $100 \%$ for matK and $98.51 \%$ for rpoc1. The identification of Phlomis aurea on species and genus levels was successful for both $r b c L$ and matK markers. Although for rpoC1, it was successful only on the family level.

The phylogenetic trees including the plant species that have the highest percentages of similarity have a fan shape (Fig 2, 3, 4 and 5), showing closely related species clustering together and relatively distantly related species scattering. DNA barcoding should replace morphological classification of plant species for species identification and genetic relationships (Hosein et al., 2017). The choice of the three genes in this study based on the Consortium for the Barcode of Life (CBOL) plant working group (2009), who has recommended $r b c L$ and matK genes as 'core barcodes' for the identification of all land plants. Recently, plant diversity was determined using $r b c L$ gene sequences as a core DNA barcoding marker (Kesanakurti et al., 2011). Moreover, matK is one of the most useful genes for identification at family, genus and species levels (Dong et al., 2012). Nowadays, methods for studying the molecular phylogeny of plants depend mainly on chloroplast genome sequencing, because of the simple and stable genetic structure of the chloroplast genome and universal primers are used for the amplification of these target sequences, such as rbcL, matK and rpoC1 have been heavily relied upon for development of markers for plant DNA barcoding (Dong et al., 2012).
The universality of barcode markers is restricted due to geographical and morphological variations and plant species evolution (Roy et al., 2010). Therefore, the universal DNA barcoding markers and the choice of the correct loci are challenging (de Groot et al., 2011).

The results of the present study show a successful identification of Phlomis aurea on the species and genus levels and it is recommended to examine other markers, such as nuclear gene markers to entirely identify the plant more accurately.

Materials and methods

\section{Samples collection}

Phlomis aurea leaf specimens and seeds were collected from shrubs grown in Wadi El Arbaien, Saint Katherine, Southern Sinai (N: 28.54123, E: 33.95736, Alt: 1704) as shown in Fig (6 and 7). Plant was identified by Dr. Omran Ghaly, Head of Plant Taxonomy Unit, Desert Research Center, Egypt and given the voucher number CAIH-1002-R. Voucher Herbarium specimens were deposited in the Herbarium of Desert Research Center (CAIH)

\section{In vitro experiments}

\section{Plant material collection and sterilization}

Phlomis aurea seeds were collected and used as plant material. Seeds were washed with detergent solution for 10 $\mathrm{min}$ to remove foreign debris. Seeds were surface sterilized in a solution of $40 \%$ commercial bleach containing $5.25 \%$ sodium hypochlorite solution for $20 \mathrm{~min}$, followed by three washes with sterile distilled water. Surface sterilization of the seeds was performed under complete aseptic conditions in a laminar air flow hood (Holten LaminAir HVR 2448, USA).

\section{In vitro germination}

Seeds were planted aseptically into jars containing MS medium (Duchefa, Haarlem, the Netherlands) supplemented with $3 \%\left(w v^{-1}\right)$ sucrose and gelled with $0.3 \%\left(w v^{-1}\right)$ phytagel (Duchefa, Haarlem, the Netherlands) and adjusted to $\mathrm{pH}$ of $5.7 \pm 0.1$ before autoclaving at a pressure of $1.06 \mathrm{~kg} \mathrm{~cm}^{-2}$ and $121^{\circ} \mathrm{C}$ for $15 \mathrm{~min}$ (Harvey Sterilemax autoclave, Thermo Scientific, USA). Cultures were incubated at $25 \pm 1^{\circ} \mathrm{C}$ at a photoperiod of $16 / 8 \mathrm{~h}$ light/darkness under cool white fluorescent tubes of 2500-3000 lux (F140t9d/38, Toshiba) for germination and seedling development. After one month of seed germination, the shoot tips and nodal segments of the emerged seedlings were excised and used as explants for micropropagation.

\section{Micropropagation}

\section{Culture establishment}

Shoot tips and stem nodal segment explants were cultured aseptically on MS medium supplemented with $3 \%\left(w v^{-1}\right)$ sucrose and $0.3 \%\left(w v^{-1}\right)$ phytagel and $0.54 \mu \mathrm{M} \beta$ naphthalene acetic acid (NAA), $2.46 \mu \mathrm{M}$ N6-(2-isopentenyl) adenine (2iP) in combination with 6-benzylaminopurine (BA) at concentrations $1.11,2.22$ and $3.33 \mu \mathrm{M}$ or kinetin (Kin) at 
concentrations of 1.16, 2.32, $3.48 \mu \mathrm{M}$ (Sigma Cell Culture, min. $90 \%$, St. Louis, USA), in addition to MS medium without growth regulators as a control, to induce new growth development. The $\mathrm{pH}$ of the medium was adjusted to $5.7 \pm 0.1$ and media were autoclaved at a pressure of $1.06 \mathrm{~kg}$ $\mathrm{cm}^{-2}$ and $121^{\circ} \mathrm{C}$ for $15 \mathrm{~min}$. Cultures were incubated at $25 \pm 1^{\circ} \mathrm{C}$ at a photoperiod of $16 / 8 \mathrm{~h}$ light/darkness under cool white fluorescent tubes of 2500-3000 lux. The percentage of survived explants (survival \%), percentage of explants forming growth (growth \%), the mean number and length of axillary shoots explant ${ }^{-1}$ were scored after eight weeks of culture on the establishment medium.

\section{Axillary shoot multiplication}

The newly developed axillary shoots were excised and cultured into jars containing MS medium supplemented with $3 \%\left(w v^{-1}\right)$ sucrose and $0.3 \%\left(w v^{-1}\right)$ phytagel and BA $(0.44$, 0.89 and $1.78 \mu \mathrm{M})$, Kin $(0.46,0.93$ and $1.86 \mu \mathrm{M})$ or $2 \mathrm{iP}(0.49$, 0.98 and $1.97 \mu \mathrm{M})$, each individually. The $\mathrm{pH}$ of the medium was adjusted, autoclaved and cultures were incubated as mentioned in the establishment stage. The mean number and length of axillary shoots explant ${ }^{-1}$ were scored after eight weeks of culture. This process was performed onto fresh medium for four successive subcultures of eight weeks each.

\section{Rooting}

Axillary shoots were transferred to rooting medium of $1 / 2$ strength MS medium supplemented with 2.46, 4.90, 9.80 and $14.7 \mu \mathrm{M}$ of indolebutyric acid (IBA; Sigma Cell Culture, min. $90 \%$, St. Louis, USA) and $1 / 2$ strength MS medium without growth regulators (as a control) for rooting induction. The $\mathrm{pH}$ of the medium was adjusted, autoclaved and cultures were incubated as mentioned the previous stages. The percentage of rooted shoots (rooting \%), the number and length of roots explant ${ }^{-1}$ were scored after four weeks of culture on the rooting medium.

\section{Acclimatization}

Rooted plantlets were removed from the nutrient medium and washed with distilled water to remove the debris on the roots. Hardening and acclimatization of the rooted plantlets were taken place gradually from the in vitro conditions to the greenhouse $\left(28 \pm 2^{\circ} \mathrm{C}, 70-80 \%\right.$ relative humidity) and was done in plastic pots containing a mixture of peat moss and soil (1:1 v:v) (Peat moos, PROMIX $\left.{ }^{\circledR}\right)$. Plants were irrigated, then covered with transparent polythene bags. The bags were perforated during the first seven days, then removed gradually to complete acclimatization.

\section{Experimental design and statistical analysis of data}

In vitro experiments were subjected to completely randomized design. Analysis of variance (ANOVA) and Duncan's multiple range test (Duncan, 1955), as modified by Snedecor and Cochran (1990), were performed to analyze the obtained data. Each experiment contained at least 15 replicates and was repeated twice. Means followed by the same letter are not significantly different at $P \leq 0.05$.

\section{DNA barcoding}

\section{DNA extraction and purification}

Phlomis aurea leaf specimens were collected and ground under liquid nitrogen to a fine powder using a sterile mortar and pestle. DNeasy Plant Kit (Qiagen, Germany) was used for DNA extraction and purification. The extracted DNA concentration and quality were estimated by running on $1 \%$ agarose gel electrophoresis, using a DNA size marker (Lambda DNA Hind III digest Phi X 174/Haelll digest).

\section{PCR and gene sequencing}

The PCR reaction was performed as mentioned by Ibrahim et al. (2016) in a total volume of $50 \mu \mathrm{L}$ PCR master mixture consisted of the following: $1 \mathrm{x}$ buffer (Promega, USA), $15 \mathrm{mM}$ $\mathrm{MgCl}_{2}, 0.2 \mathrm{mM}$ dNTPs (Promega, USA), 20 pcoml of each primer (Invitrogen, USA), 1 u of Taq DNA polymerase (GoTaq, Promega, USA), 40 ng DNA and ultra-pure water to the final volume.

DNA barcoding analysis was performed with the chloroplast DNA (cpDNA) genes; ribulose-1,5-bisphosphate carboxylase/oxygenase large subunit $(r b c L)$, maturase $\mathrm{K}$ (matK) and RNA polymerase C1 (rpoC1) regions. For PCR amplification and sequencing of $r b c L$, matK and $r p o C 1$, the primer pairs $r b c L-F$ (5'-ATG TCA CCA CAA ACA GAG ACT AAA GC-3'), rbcL- $R$ ( $5^{\prime}$-TCG CAT GTA CCT GCA GTA GC-3'), matK-F (5'-CGA TCT ATT CAT TCA ATA TTT C-3'), matK-R (5'TCTAGCACACGAAAGTCGAAGT-3') and rpoC1- $F$ (5'-GGC AAA GAG GGA AGA TTT CG-3'), rpoC1- $R$ (5'-CCA TAA GCA TAT CTT GAG TTG G-3'), were used for the PCR. Average amplicon size/bp were 692, 957 and 522 for rbcL, matK and rpoC1, respectively.

The PCR was performed with a Perkin-Elmer/GeneAmp ${ }^{\circledR}$ PCR System 9700 (PE Applied Biosystems, USA) programmed to fulfill 40 cycles after an initial denaturation cycle for $5 \mathrm{~min}$ at $94 \% \mathrm{C}$. Each cycle consisted of a denaturation step at $94{ }^{\circ} \mathrm{C}$ for $30 \mathrm{~s}$, an annealing step at 50 으 for $30 \mathrm{~s}$ and an elongation step at $72^{\circ} \mathrm{C}$ for $30 \mathrm{~s}$. The primer extension segment was extended to $7 \mathrm{~min}$ at $72^{\circ} \mathrm{C}$ in the final cycle.

The amplification products were resolved by electrophoresis in a $1.5 \%$ agarose gel containing ethidium bromide $(0.5 \mathrm{ug}$ $\mathrm{ml}^{-1}$ ) in $1 \mathrm{X}$ TBE buffer at 95 volts. A 100 bp DNA ladder (Promega, USA), was used as a molecular size standard for PCR product sizes determination. Gel images were visualized using UV transilluminator and photographed using a Gel Documentation System (BIO-RAD 2000, USA).

PCR products were purified using a QIAquick PCR Purification Kit (Qiagen, USA). The sequencing of the PCR product was carried out using the dideoxynucleotide chain termination method with a DNA sequencer (ABI 3730XL, Applied Biosystems) (Microgen, Korea) and a BigDye Terminator version 3.1 Cycle Sequencing RR-100 Kit (Applied Biosystems, USA) following the protocol supplied by the manufacturer.

\section{Assignment of species}

DNA barcoding of Phlomis aurea was carried out using the Basic Local Alignment Tool (BLAST) available on the National Centre of Biotechnology Information (NCBI) website. All sequences were submitted to GenBank, USA. GenBank 
provided accession numbers for the nucleotide sequences of MK628683, MK628684 and MK628686.

BLAST searches were applied to all produced sequences using the available online databases (DDBJ/EMBL/GenBank) and were analyzed using BLASTN 2.8.1 program (http://www.ncbi.nlm.nih.gov/BLAST) and aligned using Align Sequences Nucleotide BLAST. Species identification was considered successful only when the highest maximal percent identity included a single species and scored $>97 \%$ (de Groot et al., 2011). Phylogenetic analysis was conducted using MAFFTv6.864, http://www.genome.jp/tools-bin/mafft, then the phylogenetic trees were generated.

\section{Conclusion}

Phlomis aurea is an important plant ecologically, medicinally and economically and thus, it is an endangered plant that needs a strict conservation plan. In this study, identification of the plant using DNA barcoding was carried out and nuclear markers should be tested for the complete identification of the plant. Also, the first protocol for efficient micropropagation of Phlomis aurea was established in the present study. This protocol should be urgently applied to conserve the plant even in a botanical garden as a first step.

\section{Acknowledgement}

The authors are thankful to Dr. Ibrahim Abdelrafee El Gamal, Nature Conservation Sector, Egyptian Environmental Affairs Agency, Southern Sinai, Egypt for his help in collection of plant specimens.

\section{References}

Abdelsalam A, Chowdhury K, El-Bakry A (2017) Micropropagation through in vitro tillering from seed cultures of the medicinal plant Cymbopogon schoenanthus subsp. proximus. Asian J Appl Sci. 5(1): 31-40.

Aicha N, Rachida TC, Abdelmalek ELM (2013) Micropropagation of Thymus satureioides Coss. an endangered medicinal plant of Morocco J Agr Technol. 9: 487-501.

Akhtar G, Jaskani MJ, Sajjad Y, Akram A (2016) Effect of antioxidants, amino acids and plant growth regulators on in vitro propagation of Rosa centifolia. Iran J Biotechnol. 14:e1152.

Akin-Idowu PE, Ibitoye DO, Ademoyegun OT (2009) Tissue culture as a plant production technique for horticultural crops. Afr J Biotechnol. 8(16): 3782-3788.

Amor I, Boubaker J, Sgaier MB, et al. (2009) Phytochemistry and biological activities of Phlomis species. J Ethnopharmacol. 125: 183-202.

Arab, MM, Yadollahi A, Shojaeiyan A, Shokri S., Ghojah SM (2014) Effects of nutrient media, different cytokinin types and their concentrations on in vitro multiplication of $\mathrm{G} \times \mathrm{N} 15$ (hybrid of almond $\times$ peach) vegetative rootstock. Journal of Genetic Engineering and Biotechnology 12(2): 81-87.

Arikat NA, Jawad FM, Karam NS, Shibli RA (2004) Micropropagation and accumulation of essential oils in wild sage (Salvia fruticosa Mill.). Sci Hort. 100: 193-202.
Asgarpanah J, Hashemi SJ, Hashemi E, Askari K (2017) In vitro antifungal activity of some traditional Persian medicinal plants on pathogenic fungi. Chin J Integr Med. 23(6): 433-437.

Bajalan I, Rouzbahani R, Pirbalouti AG, Maggi F (2017) Variation on chemical composition and antibacterial activity of the essential oil of wild populations of Phlomis olivieri. Chem Biodivers. 14(5): e1600444.

Bakker JP, Berendse F (1999) Constraints in the restoration of ecological diversity in grassland and heathland communities. Trends Ecol Evol. 14(2): 63-68.

Bouhouche N, Ksiksi T (2007) An efficient in vitro plant regeneration system for the medicinal plant Teucrium stocksianum Boiss. Plant Biotechnol Rep.1: 179-184.

Boulos L (2002) Flora of Egypt. Vol. 3. Al-Hadara Publishing, Cairo, Egypt

Boulos L (2008) Flora and vegetation of the deserts of Egypt. Fl. Medit. 18: 341-359.

CBOL Plant Working Group (2009) A DNA barcode for land plants. Proceedings of the National Academy of Sciences of the United States of America, 106: 12794-12797.

Dakah A, Zaid S, Suleiman M, Abbas S, Wink M (2014) In vitro propagation of the medicinal plant Ziziphora tenuior L. and evaluation of its antioxidant activity. Saudi J Biol Sci. 21(4): 317-323.

de Groot GA, During HJ, Maas JW, Schneider H, et al. (2011) Use of $r b c L$ and $t r n L-F$ as a two-locus DNA barcode for identification of NW-European ferns: an ecological perspective. PLoS One 6: e16371.

Devi WS, Bengyella L, Sharma GJ (2012) In vitro seed germination and micropropagation of edible bamboo Dendrocalamus giganteus Munro using seeds. Biotechnology DOI: 10.3923/biotech.2012

Dong W, Liu J, Yu J, Wang L, Zhou S (2012) Highly variable chloroplast markers for evaluating plant phylogeny at low taxonomic levels and for DNA barcoding. PLoS One 7(4): e35071.

Dolcet-Sanjuan R, Claveria E, Gruselle R, Meier-Dinkel A, JayAllemand C, Gaspar T (2004) Practical factors controlling in vitro adventitious root formation from walnut shoot microcuttings. J Am Soc Hortic Sci.129: 198-203.

Duncan DB (1955) Multiple range and multiple " $F$ " test. Biometrics 11: 1-42.

El-Banhawy A, Al-Juhani W (2019) DNA barcoding and phylogeny of Phlomis aurea (Lamiaceae) endemic to Sinai Peninsula, Egypt. Pak J Bot. 51(4): 1263-1271.

Fay MF (1994) In what situations is in vitro culture appropriate to plant conservation? Biodivers Conserv. 3: 176-183.

Frabetti M, Gutiérrez-Pesce P, Mendoza-de Gyves E, Rugini E (2009) Micropropagation of Teucrium fruticans L., an ornamental and medicinal plant. In Vitro Cell Dev Biol. Plant 45: 129-134.

George EF, Hall MA, Klerk GJD (2008) Plant propagation by tissue culture. Springer, Netherlands.

Gonçalves S, Romano A (2013) In vitro culture of lavanders (Lavandulaspp.) and the production of secondary metabolites. Biotechnol Adv. 31: 166-174.

Hosein FN, Austin N, Maharaj S., Johnson W, Rostant L, Ramdass AC, and Rampersad SN (2017) Utility of DNA barcoding to identify rare endemic vascular plant species in Trinidad. Ecol Evol. 7(18): 7311-7333. 
Ibrahim SD, Adawy SS, Atia MAM, Alsamman AM, Mokhtar MM (2016) Genetic diversity, variety identification and gene detection in some Egyptian grape varieties by SSR and SCoT markers. Plant Omics 9(5): 311-318.

IUCN (2019) The IUCN (International Union for Conservation of Nature) Red List of Threatened Species. Available at: www.iucnredlist.org/species/84119983/84119987

Kamel MS, Mohamed KM, Hassanean HA, Ohtani K, Kasai R, Yamasaki $\mathrm{K}(2000)$ Iridoid and megastigmane glycosides from Phlomis aurea. Phytochemistry 55: 353-357.

Kesanakurti PR, Fazekas AJ, Burgess KS, Percy DM et al. (2011) Spatial patterns of plant diversity below-ground as revealed by DNA barcoding. Mol Ecol. 20: 1289-1302.

Khafagi O, Hatab EE, Omar K (2012) Challenges towards Hypericum sinaicum conservation in south Sinai, Egypt. Jordan J Biol Sci. 6(2): 116-126.

Kieber JJ, Schaller GE (2004) Cytokinins. The Arabidopsis book 12: e0168.

Lebedev V, Arkaev M, Dremova M, Pozdniakov I, Shestibratov K (2019) Effects of growth regulators and gelling agents on ex vitro rooting of raspberry. Plants 8(3): 1-10.

Li Q, Yang S, Yang S, Xin F, Wang M (2015) Anti-inflammatory activity of phlomisoside $\mathrm{F}$ isolated from Phlomis younghusbandii Mukerjee. Int Immunopharmacol. 28(1): 724-30.

Mathiesen C, Scheen AC, Lindqvist C (2011) Phylogeny and biogeography of the lamioid genus Phlomis (Lamiaceae). Kew Bull. 66: 83-99.

Merouane A, Saadi A, Noui A (2018) Impact of removal of micro and nano sized particles on the phenolic content and antioxidant activity: study on aqueous and methanolic leaves extracts of Phlomis crinita. Ind Crop Prod. 114: 132136.

Murashige T, Skoog $F$ (1962). A revised medium for rapid growth and bioassays with tobacco tissue cultures. Physiol Plant. 15: 473-497.

Omar K (2017) Phlomis aurea. The IUCN Red List of Threatened Species 2017: e.T84119983A84119987. Available at: http://dx.doi.org/10.2305/IUCN.UK.20173.RLTS.T84119983A84119987.en

Oseni OM, Pande V, Nailwal TK (2018) A review on plant tissue culture, a technique for propagation and conservation of endangered plant species. Int J Curr Microbiol App Sci. 7(7): 3778-3786.

Papafotiou M, Kalantzis A (2009) Seed germination and in vitro propagation of Sideritis athoa. Acta Hort 813: 471476.

Papafotiou M, Martini AN (2014) In vitro seed and clonal propagation of the Mediterranean aromatic and aedicinal plant Teucrium capitatum. HortScience 51(4): 403-411.

Pernisova M, et al. (2009) Cytokinins modulate auxininduced organogenesis in plants via regulation of the auxin efflux. Proc Natl Acad Sci. USA 106: 3609-3614.

Pernisova M, et al. (2018) Cytokinin signalling regulates organ identity via the AHK4 receptor in Arabidopsis. Development 145: 1-11.

Rosspopoff O, et al. (2017) Direct conversion of root primordium into shoot meristem relies on timing of stem cell niche development. Development 144: 1187-1200.
Saha S, Dey T, Ghosh P (2010) Micropropagation of Ocimum kilimandscharicum Guerke (Labiatae). Acta Biol Cracov Ser Bot, 52: 50-58.

Sarkhail P, Sahranavard S, Nikan M, Gafari S, Eslami-Tehrani B (2017) Evaluation of cytotoxic activity of extracts from six species of Phlomis genus. J Appl Pharm Sci. 7(2): 180184.

Serag Marwa M, Moustafa AA, Qiqa, Sara S (2018) Impact of climate change on surviving of Phlomis aurea as an endemic species growing in Southern Sinai, Egypt. Catrina 17(1): 29-35.

Shabana HAM (2013) Variability among Phlomis aurea Decne. populations in Southern Sinai. M.Sc. Thesis, Botany Department, Faculty of Science, Tanta University.

Shaltout KH, Ahmed DA, Shabanah HAM (2016) Distribution of the associated species with Phlomis aurea Decne along an elevation gradient in Southern Sinai, Egypt. International Journal of Mediterranean Ecology 42(1): 6579.

Sobeh M, Mamadalieva NZ, Mohamed T, Krstin S, Youssef FS, Ashour ML, Azimova SS, Wink M (2016) Chemical profiling of Phlomis thapsoides (Lamiaceae) and in vitro testing of its biological activity. Med Chem Res. 25(10): 2304-2315.

Snedecor GW, Cochran WG (1990) Statistical methods. $8^{\text {th }}$ edn. lowa State University Press, Ames, lowa, USA.

TäckholmV (1974) Students' flora of Egypt. $2^{\text {nd }}$ edn. Beirut, Cairo University, Egypt.

Tsafouros A, Roussos PA (2019) First report of Krymsk ${ }^{\circledast} 5$ (cv. VSL 2) cherry rootstock in vitro propagation: Studying the effect of cytokinins, auxins and endogenous sugars. Not Bot Horti Agrobo. 47(1): 152-161.

Turker AU, YIdrm AB (2013) Evaluation of antibacterial and antitumor activities of some Turkish endemic plants. Trop Journal Pharm Res. 12(6): 1003-1010.

Rasool R, Kamili AN, Ganai BA, Akbar S (2009) Effect of BAP and NAA on shoot regeneration in Prunella vulgaris. J Nat Sci Math. 3: 21-26.

Rout GR (2004) Effect of cytokinins and auxins on micropropagation of Clitoria ternatea L. Biol Lett. 41: 2126.

Roy S, Tyagi A, Shukla V, Kumar A, Singh UM, Chaudhary LB, et al. (2010) Universal plant DNA barcode loci may not work in complex groups: A case study with Indian berberis species. PLoS ONE 5(10): e13674.

Yancheva S, Kondakova V (2016) Plant tissue culture technology: Present and future development. In: Pavlov A, Bley $T$ (eds) Bioprocessing of plant in vitro systems, Reference Series in Phytochemistry. Springer International Publishing AG.

Wang L, Du Y, Rahman MdM, Tang B, Fan L, Kilaru A (2018) Establishment of an efficient in vitro propagation system for Iris sanguinea. Sci Rep. 8: Article number 17100 (2018).

Zhang H, Horgan KJ, Reynolds PHS, Jameson PE (2010) 6Benzyladenine metabolism during reinvigoration of mature Pinus radiata buds in vitro. Tree Physiol. 30: 514526.

Zuzarte MR, Dinis AM, Cavaleiro C, Salgueiro LR, Canhoto JM (2010) Trichomes, essential oils and in vitro propagation of Lavandula pedunculata (Lamiaceae). Ind Crops Prod. 32: 580-587. 